\title{
جريمة التهرب الضريبي في التشريع الجزائري
}

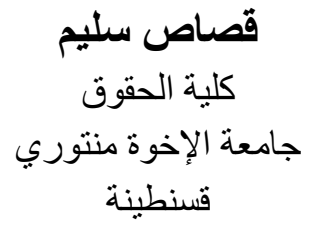

مل ملفص:

Abstract:

In Algeria The Sanctions Regime for Fiscal Fravel is Frankly Reprissive, Since it Allows Onthe one Hande the Cumulation of Penalties Without Any Limite, And The Criminalization of Froud When the Amount of Duty Evaded Exceeds a Certain the Shold And on The Other Hand it Does not Provide and Guarantée for The tax Payer Sued for Fraud Againstan Administration Invested in the Matter of a Power Largely Discvertionary. 


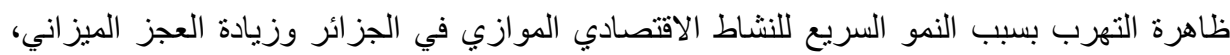

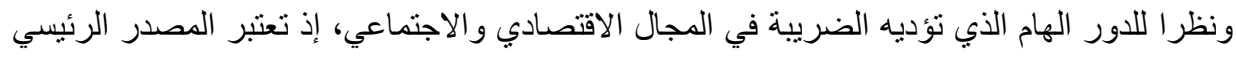

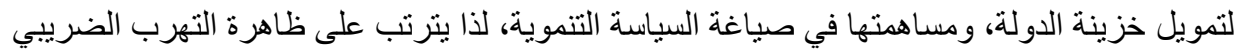

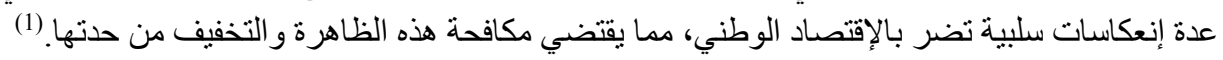

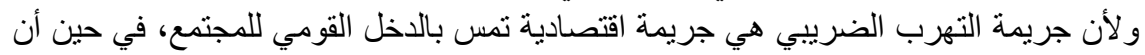

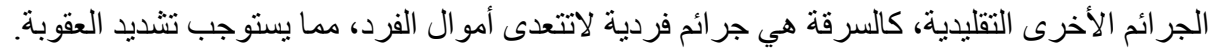

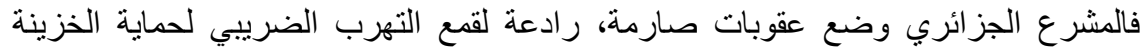

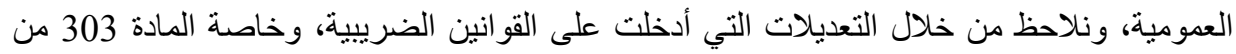

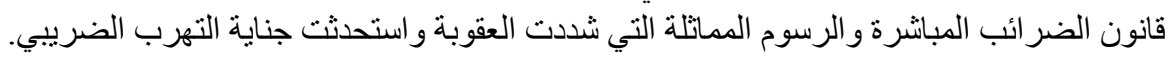

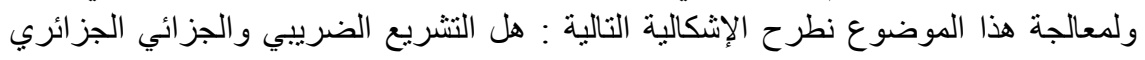

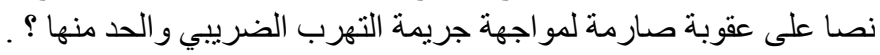

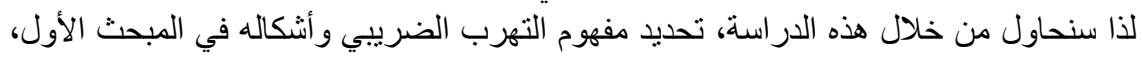

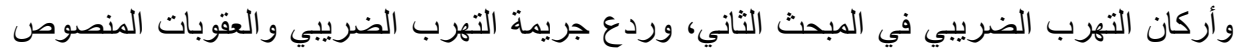

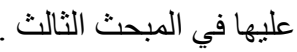
المبحث الأول : مفهوم وأشكال التهرب الضريبي

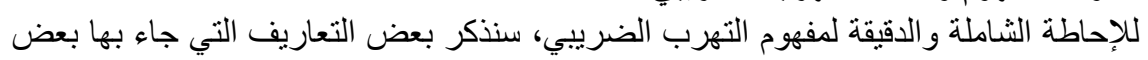

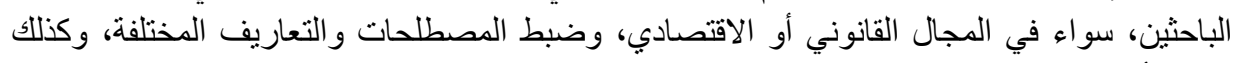

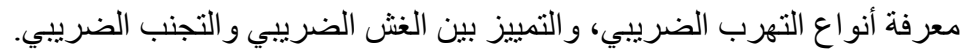

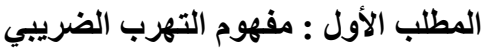

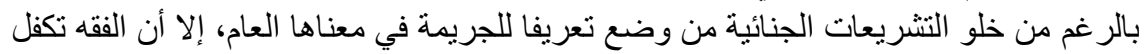

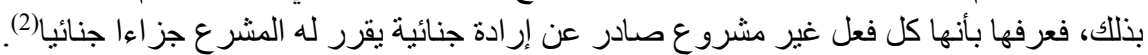

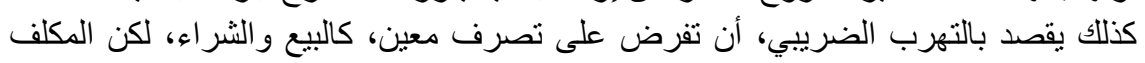

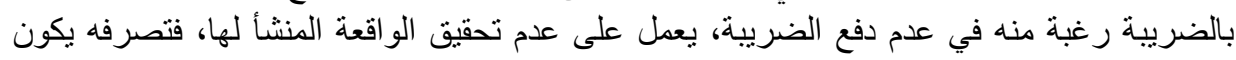

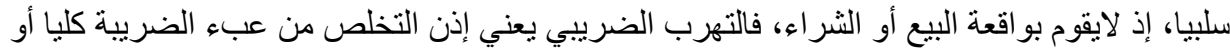

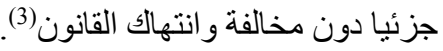
ويعرف كذلك كل نشاط خارجي لإنسان يفرض لهاب القان القانون عقابا، ويقصد بالنشاط هنا الفعل

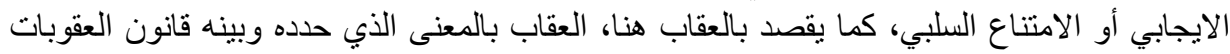

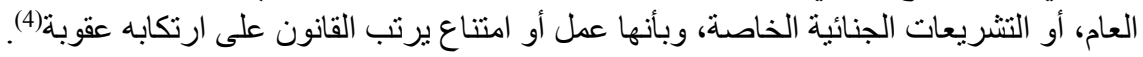

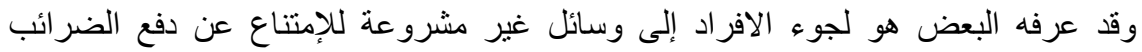

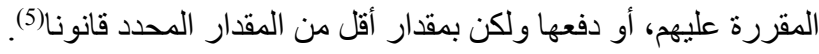

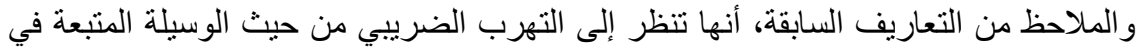

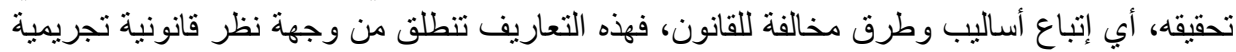

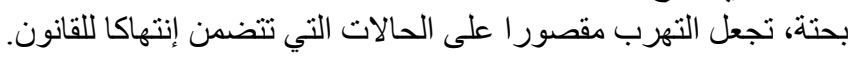

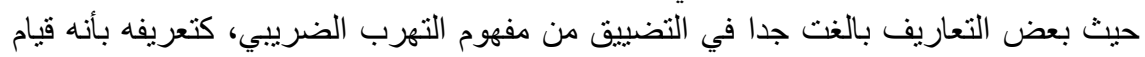

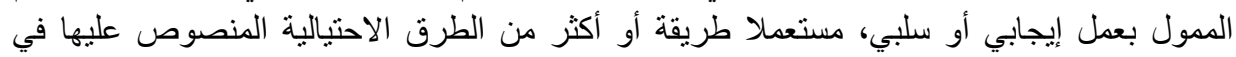

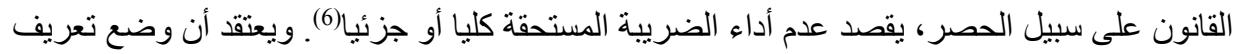
واضح للتهرب الضريبي تنشأ من خلال تحديد مضمونه الاقتصادي و القانوني. 
من الناحية الاقتصادية، بعتبر التهرب الضريبي تصرف يترتب عليه نقص في الحصيلة

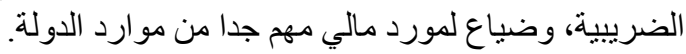

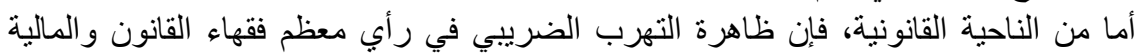

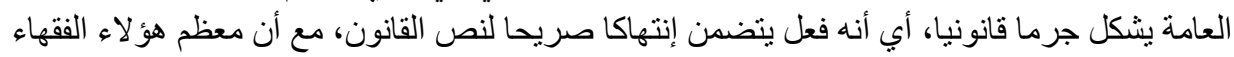

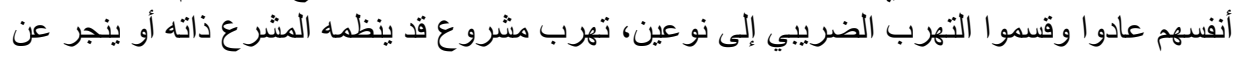

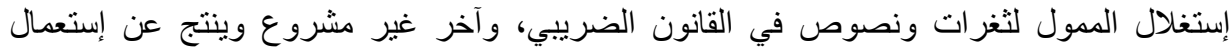
أساليب مخالفة للقانون (7).

ويتققد بضرورة النظر إلى مفهوم التهرب الضريبي من وجهة نظر اقتصادية واسعة، كونه

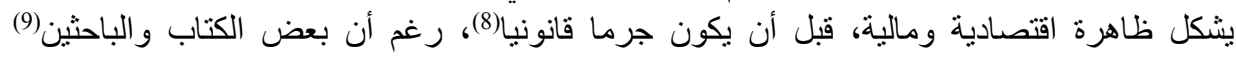

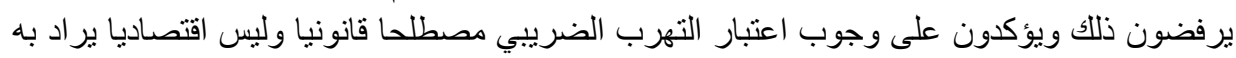
التحايل على القانون لإخفاء الأرباح الحقيقية للمولين.

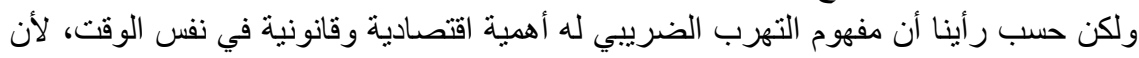

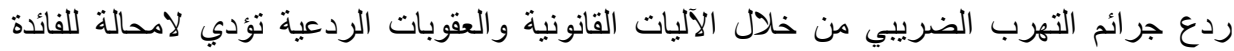

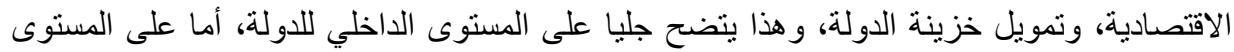

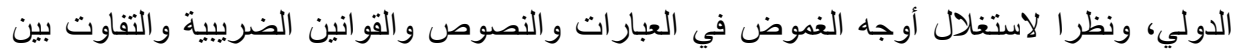

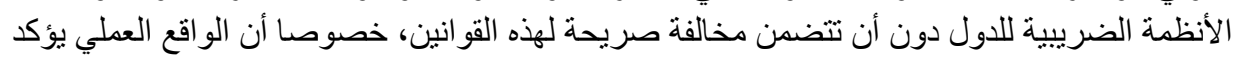

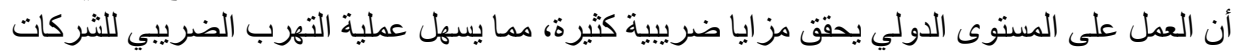

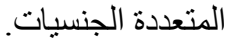

وفي الأخير نخلص إلى تعريف التهرب الضريبي عموما بأنه ظاهرة قانونية واقتصادية

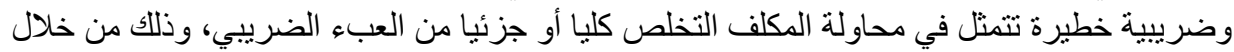

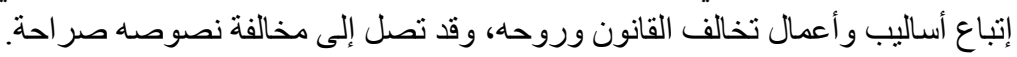
المطلب الثاني أشكال التهرب الضرال الضريبي الضون

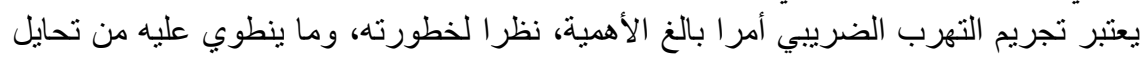

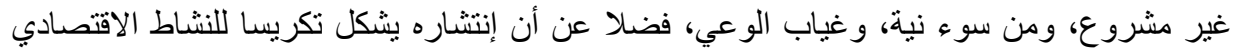

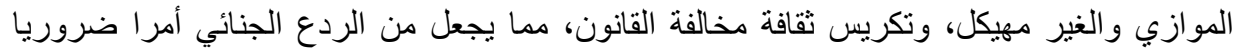

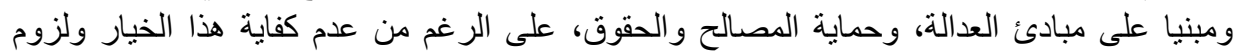
تعزيزه بتدابير وقائية غير جنائية فقط.

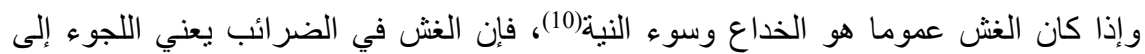

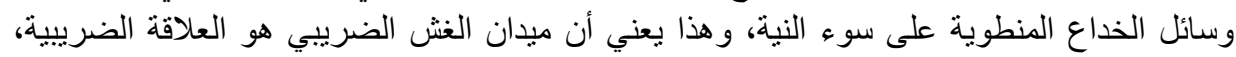

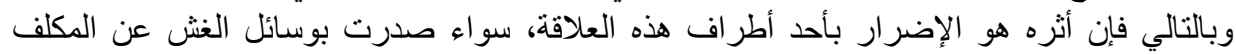

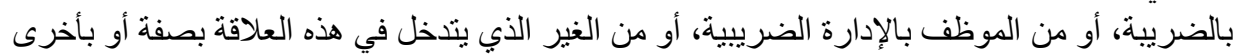

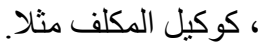

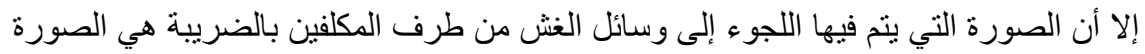

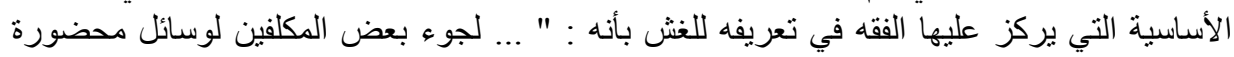
التملص من الالتز امات التي تتص عليه فئها هذه القو انين "(11).

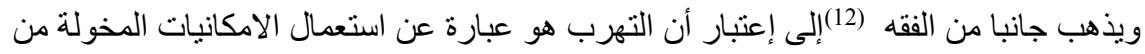

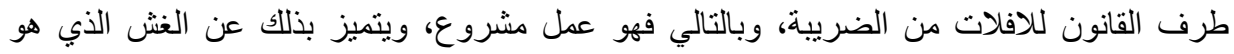




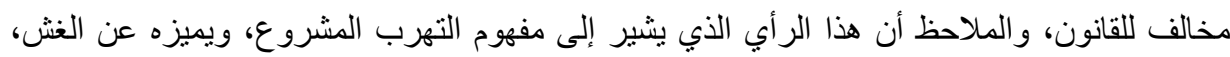

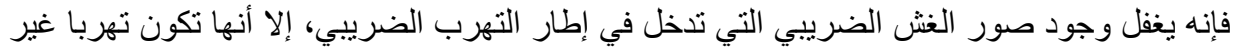

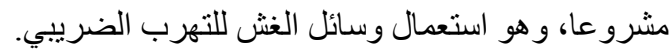

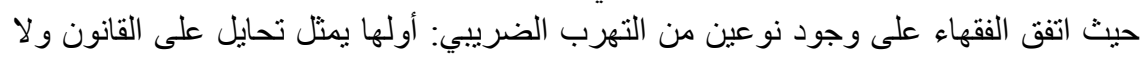

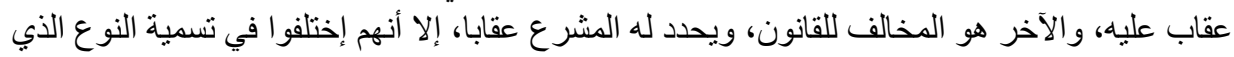

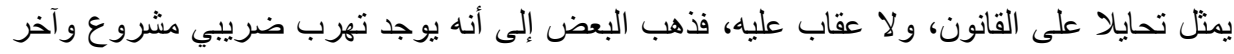

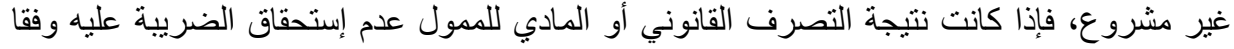

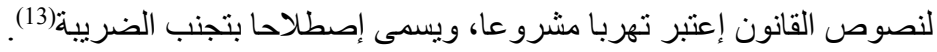

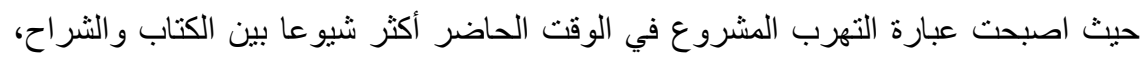

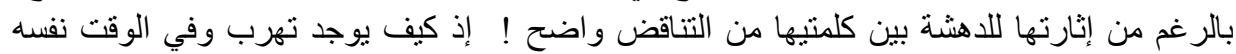

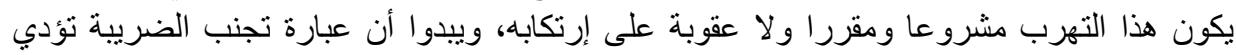
المعنى الصحيح(14). إن كلمة التهرب وحدها تنصب على حالات التهرب الإجر امي أو الجنائي، والذي يقع عقابه

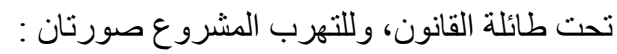

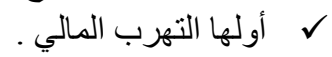

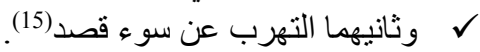

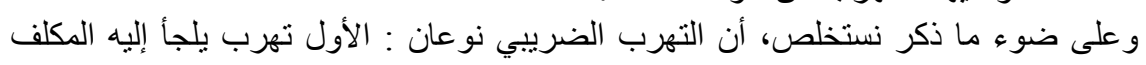

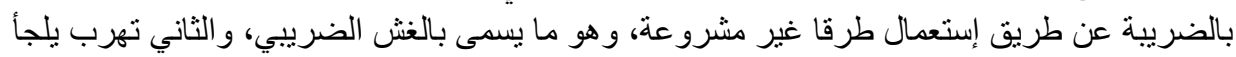

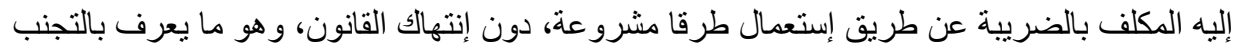

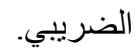
الفرع الأول : التجنب الضريبي أصبح تعبير التجنب الضريبي الضيب، شائعا في القو انين الضريبية و الدراسات الفقهية(16)، وقد لايكون

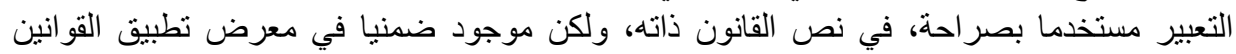
و القرارات الإدارية للتأكد من تحقيق العدالة الضريبية. ويعتبر مصطلح التجنب الضريبي من إبداعات الاقتصاديين الذي شاع في سبراء سبعينيات القرن

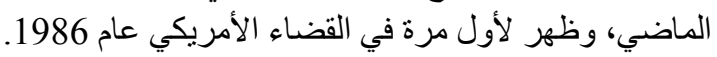

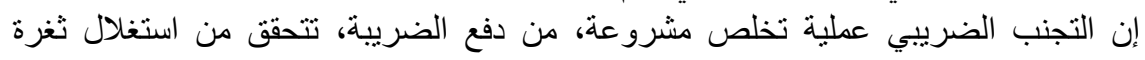

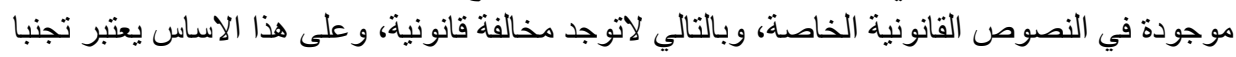

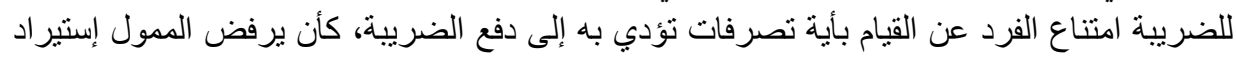

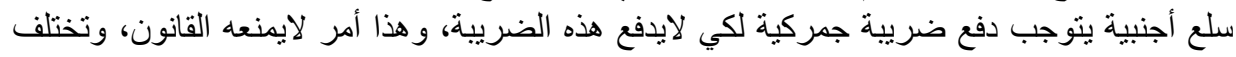

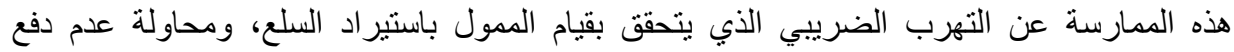

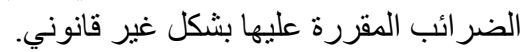

كما بعد تجنبا للضريبة استعمال الممول الطرق القانونية لتكييف الوضع المبع المالي لتقليل قيمة

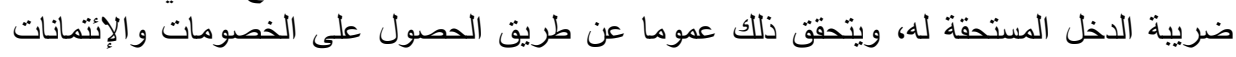

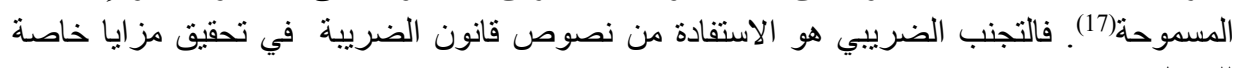


فتعريف منظمة التعاون الاقتصادي والتنمية، بأن التجنب الضريبي هو ترتيب أمور الممول بما

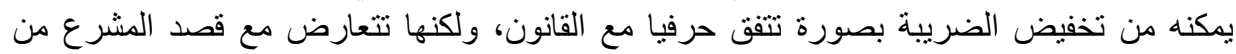

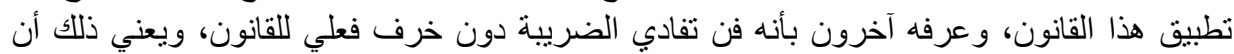

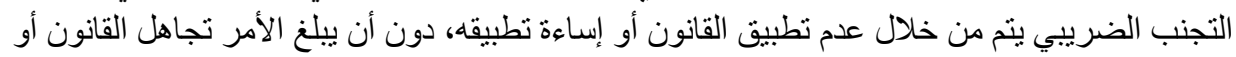

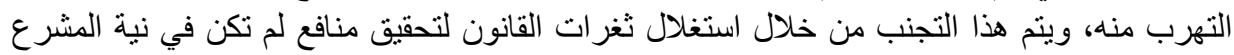

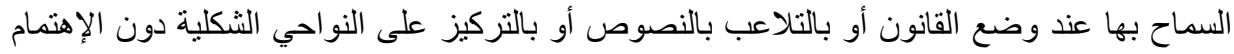
بجوهر المعاملات التي يعني بها هذا القانون (18). و هناك تعريف يقول بأنه يقصد بتجنب الضريبة أن يتخلص المكلف القانوني عن دفع الضريبة

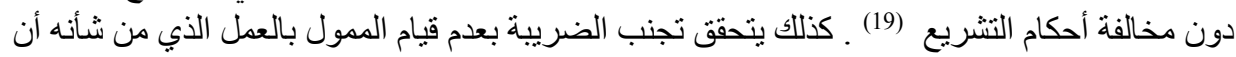

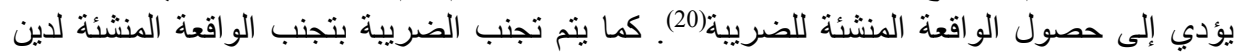

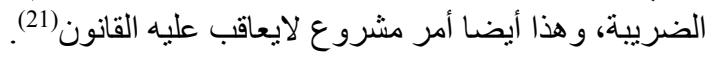

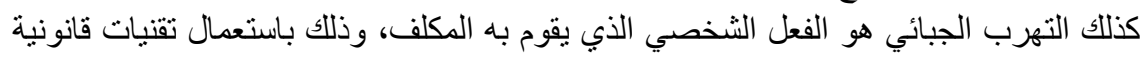
مؤسسة معتمدة على حرية التسيير، تسمح لله باختيار وضعية جبائية محددة للحصول على لفئل نتائج

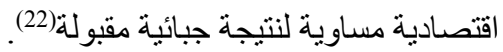

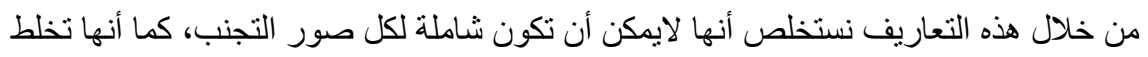

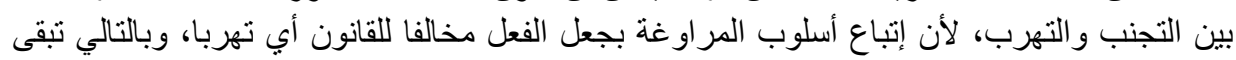

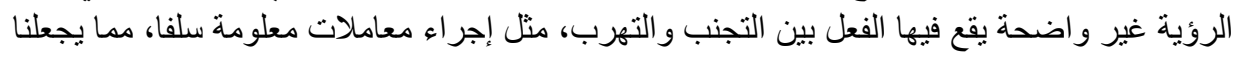

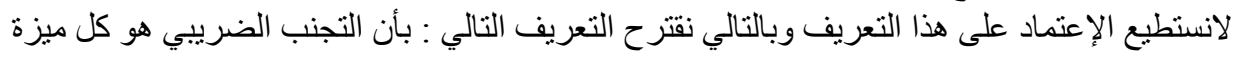

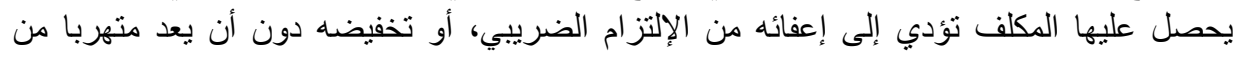

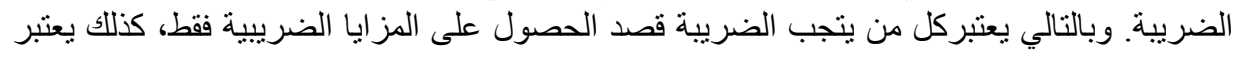

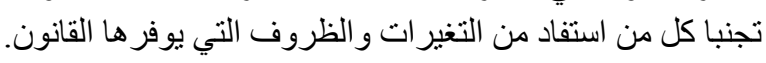

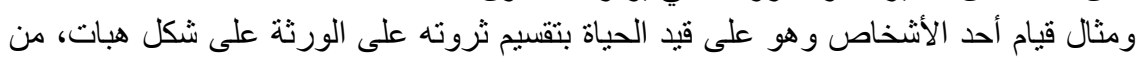

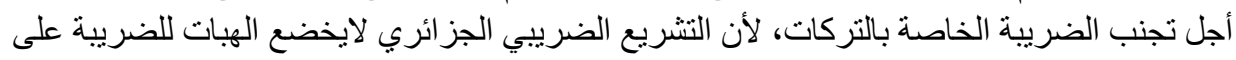

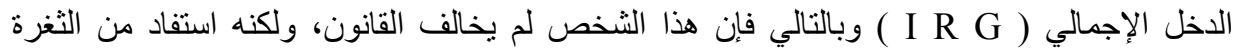

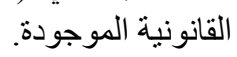
الفرع الثاني : الغش الضريبي

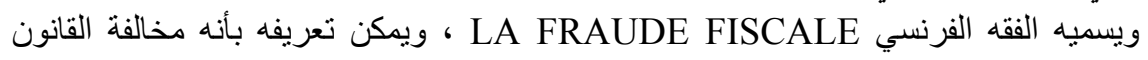

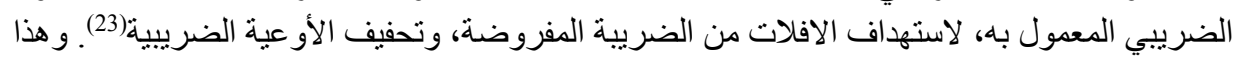

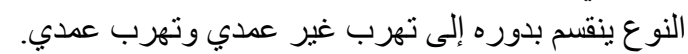

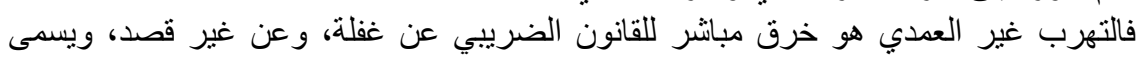

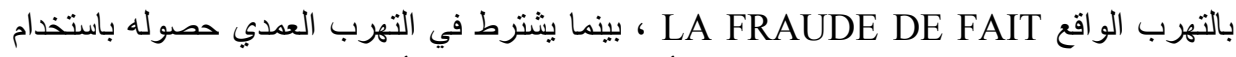

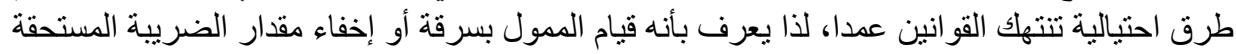
بأية وسيلة احتيالية(24). فمصطلح LA FRAUDE FISCALE ، قد أطلقه الفقه الفرنسي فقط على كل الحالات التي

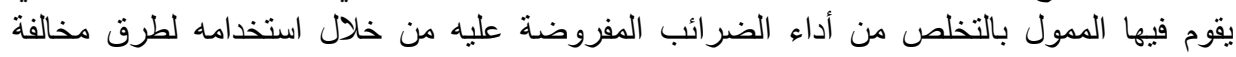

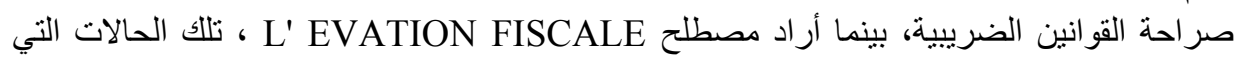


يستطيع الممول بموجبها التحايل على القو انين الضرييية ومر او غتها دون مخالفتها صر احة للإفلات من

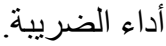

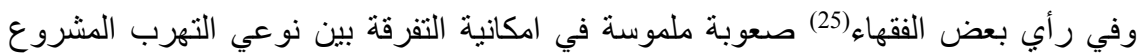

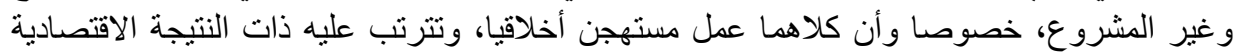

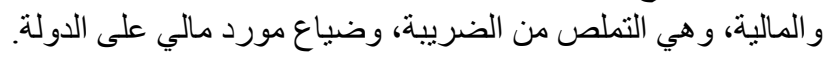

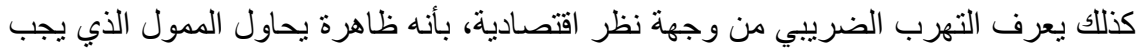

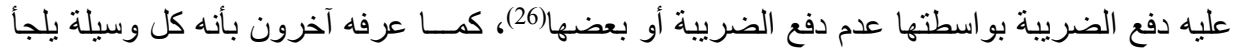

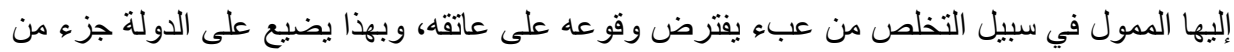

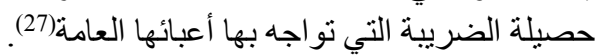

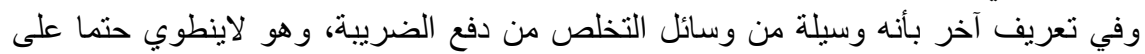
العبث بالقانون أو الاخلال بأحكامه، لأنه قد ينحصر في تجنب العمل أو التصرف الذب الذي قد يؤدي إلى لإنى

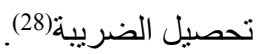

ويلاحظ من خلال هذه التعاريف أنها تنظر إلى التهرب الضريبي من حيث النتيجة المترتبة عليه,

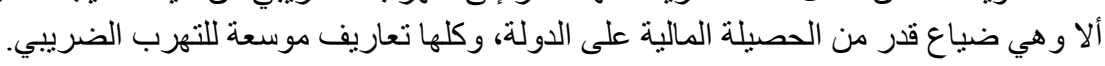

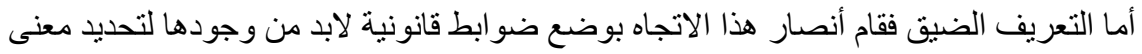

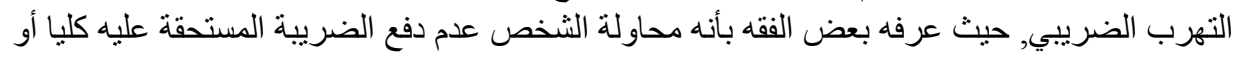

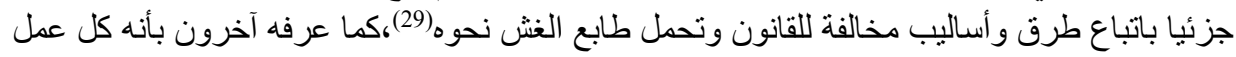

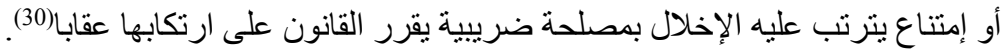

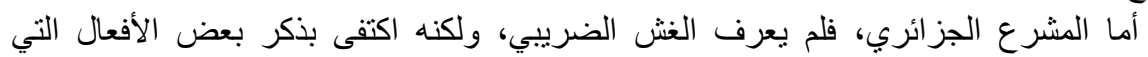

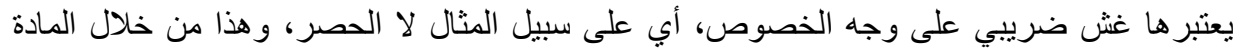

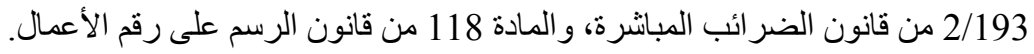

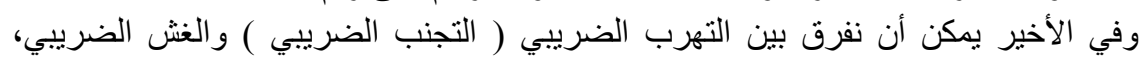

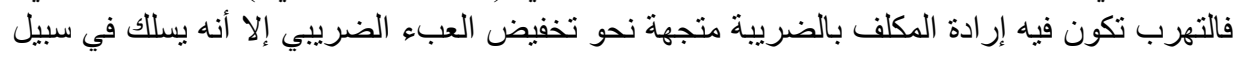

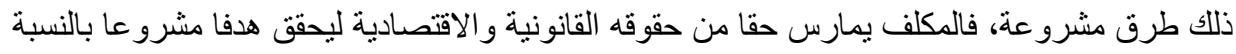

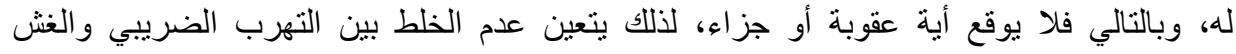

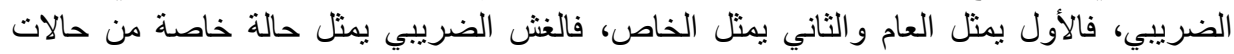

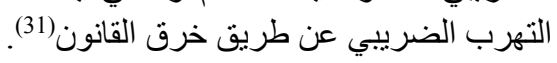
المبحث الثاني : أركان التهرب الضريب التريبي

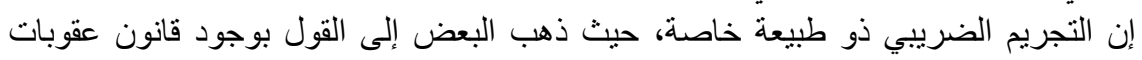

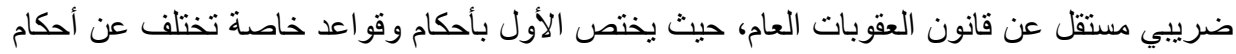

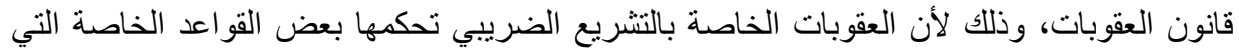

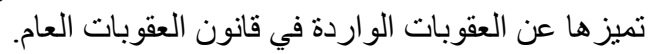

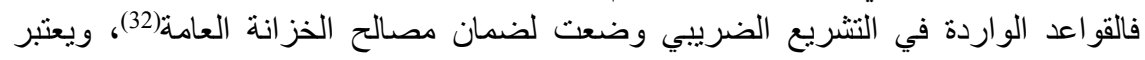

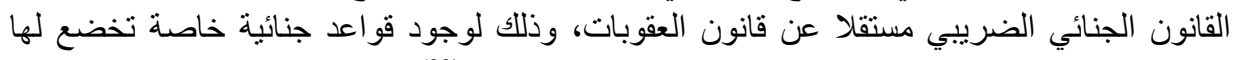

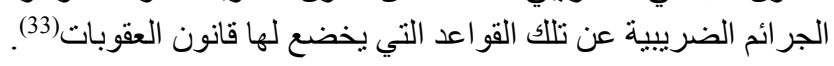
إن التهرب الضريبي، هو جريمة تمس بكيان الاقتصاد الوطني، فهو يعتبر من الجرائم

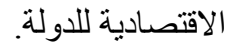




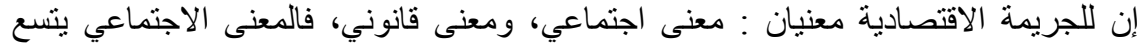

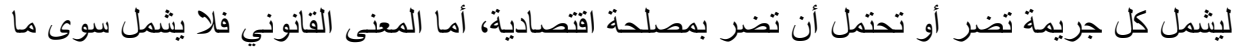
يمس بسياسة الدولة الاقتصادية(34).

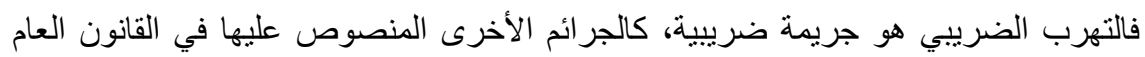

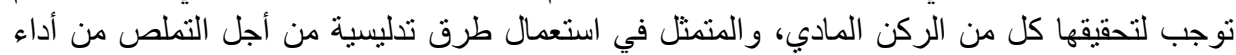

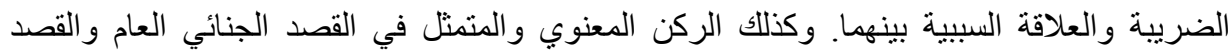

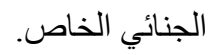

المطلب الأول : الركن المادي

يقصد بالركن المادي للجريمة هو كل من يدخل في كبانها وتكون له طبيعة مادية وتلمسه

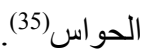

فلا يتصوروجود جريمة بدون ركن مادي، ذلك أن القانون لايعاقب على مجرد الأفكار

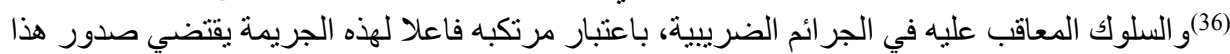

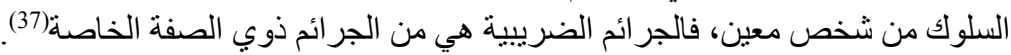

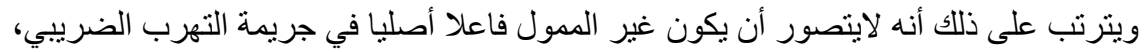

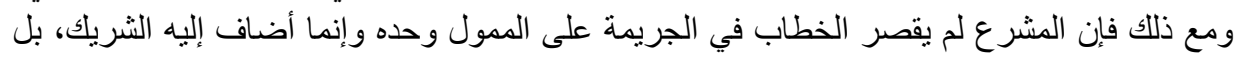

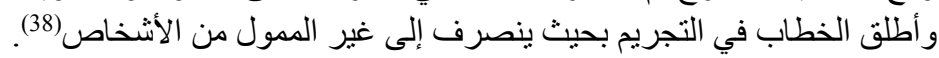

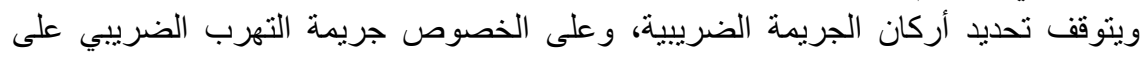

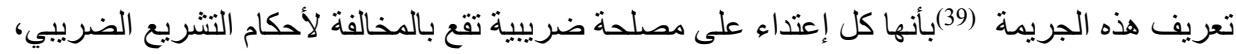

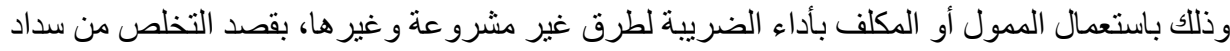

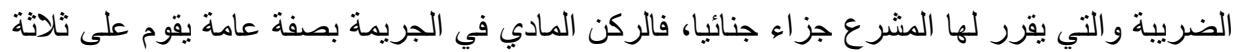

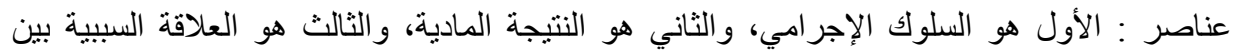

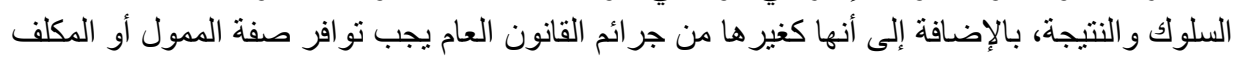

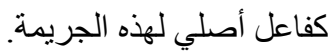

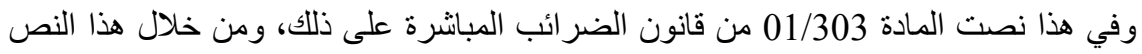

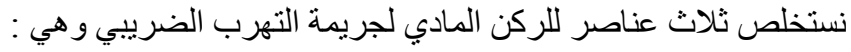

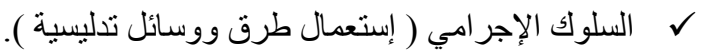

$$
\begin{aligned}
& \text { ل }
\end{aligned}
$$

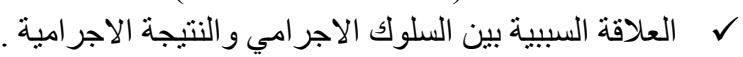

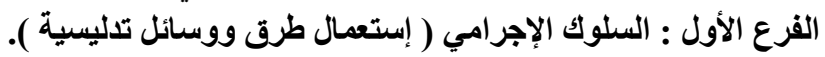

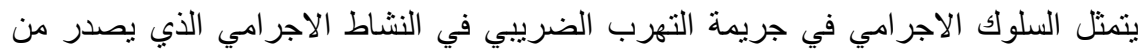

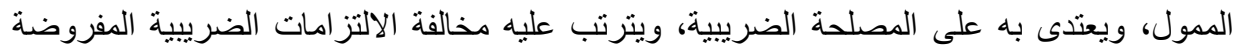

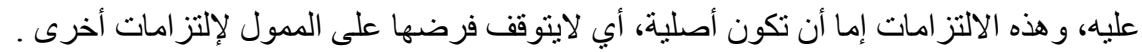

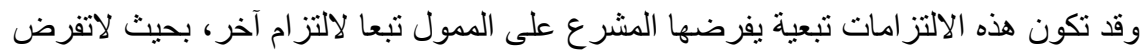

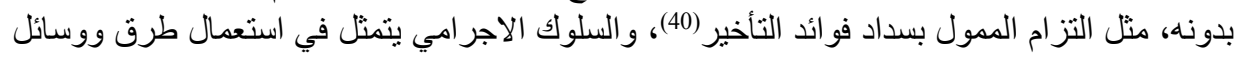

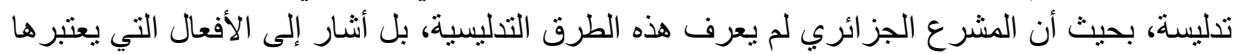

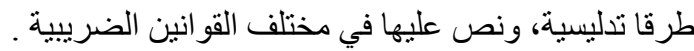
الفرع الثاني : النتيجة الاجرامية ( التخلص من الضريبة ) 
النتيجة الاجرامية هي الأثر المترتب على السلوك الاجرامي، والذي يأخذه المشرع بعين الاعتبار في التكوين القانوني للجريمة(41).

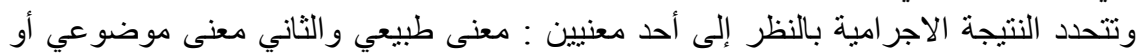
قانوني، فالنتيجة بمعناها الطبيعي يقصد بها التغيير الذي يحدثه النشاط الاجر التي امي في في العالم الخارجي،

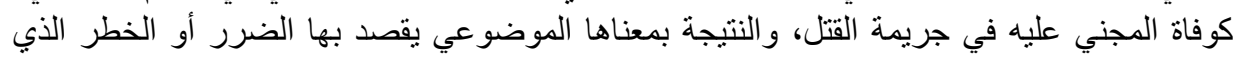
يصيب أو يهذد الحق الذي تحميه القاعدة الجنائية(42).

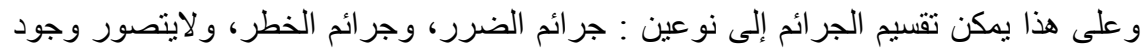

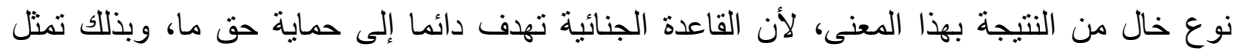

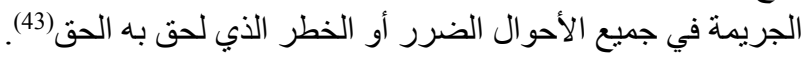

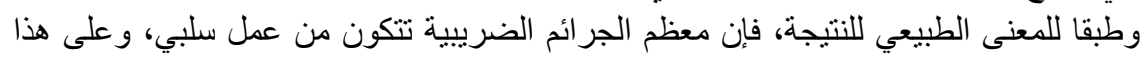

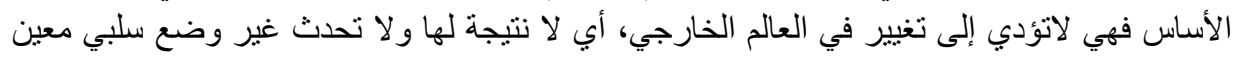

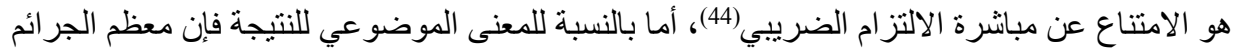

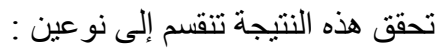
النوع الأول : جرائم تلحق ضررا بالمصلحة الضريبية، وهي جرائم الامتتاع عن أداء الضر ائب.

النوع الثاني : جر ائم تعرض المصلحة الضريبية للخطر ، وهي غالبية الجر ائم الضريبية.

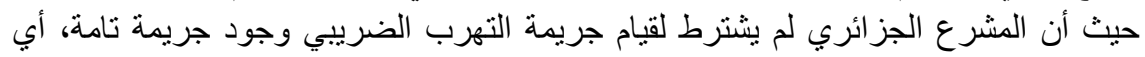

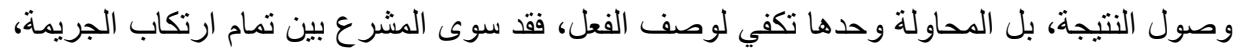

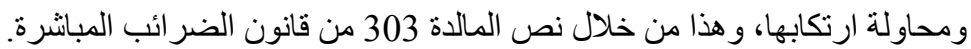
الفرع الثالث : العلاقة السببية

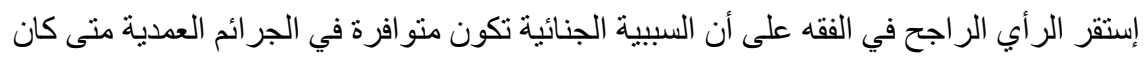

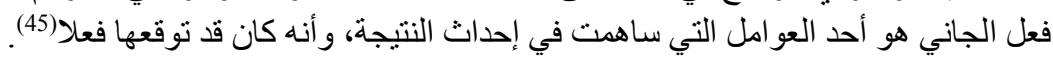

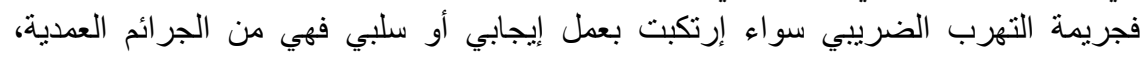

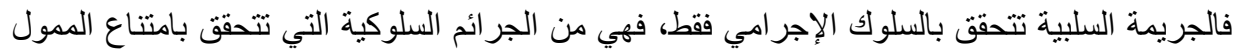

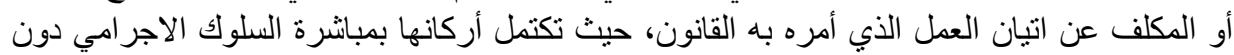

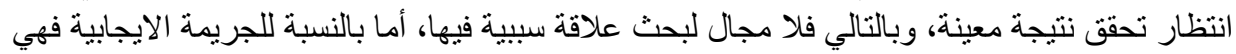

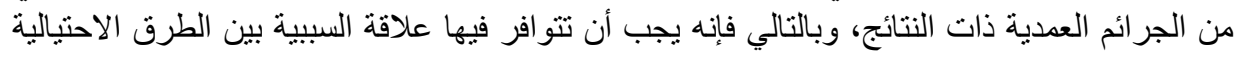

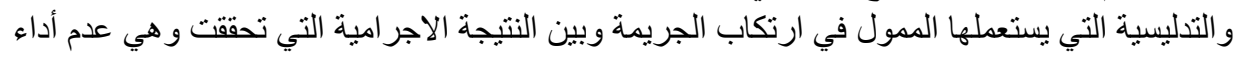

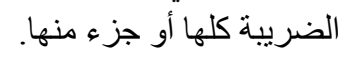
المطلب الثاني : الركن المعنوي

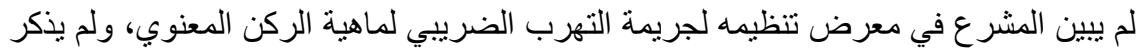

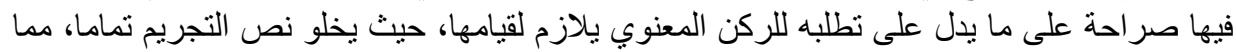

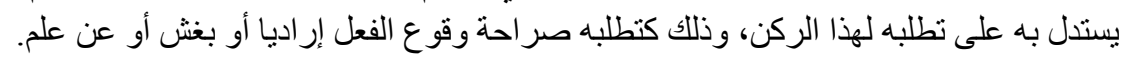

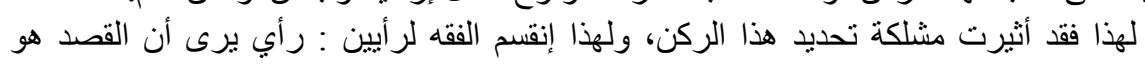

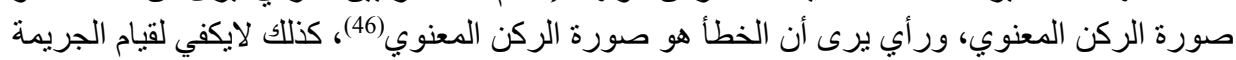

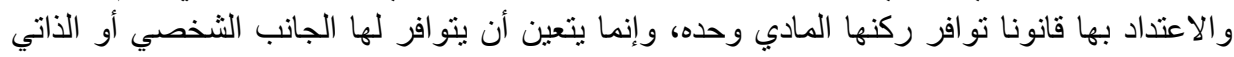

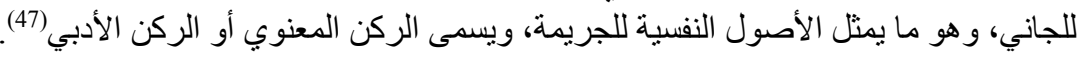


ومن المعروف أن هذه الجريمة تعد من الجرائم العمدية، فيتعين نوافر القصد الجنائي العام لقيامها، وتبدو صعوبة البحث في مدى إنتر اطن التو افر القصد الجنائي الخاص. الفرع الأول : القصد العام القام

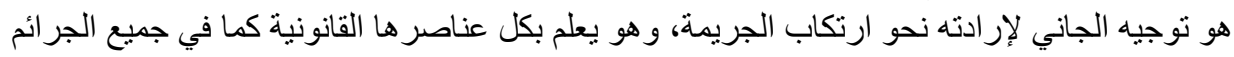

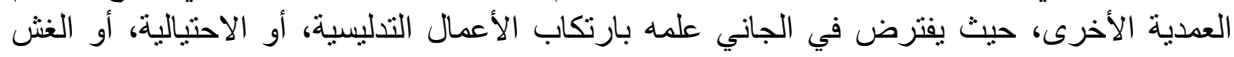

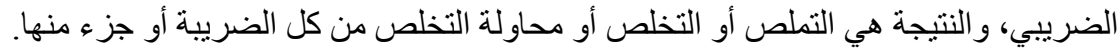

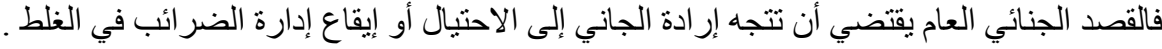

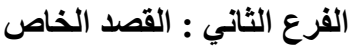
إذا كان القصد العام ينطلب توجيه الجاني لإر ادته نحو ارتكاب الجريمة، عالما بكل الإن أركانها

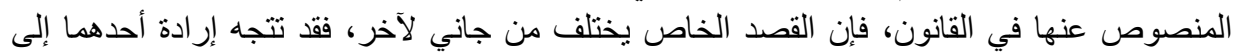

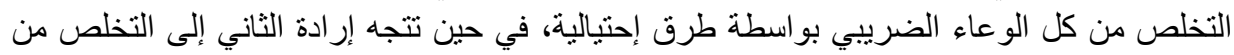

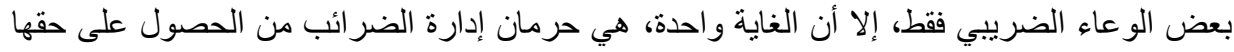

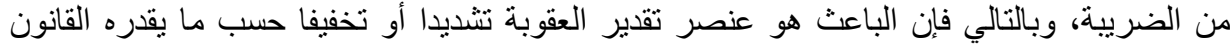

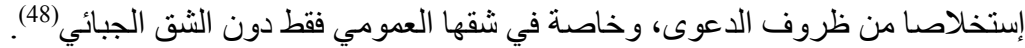

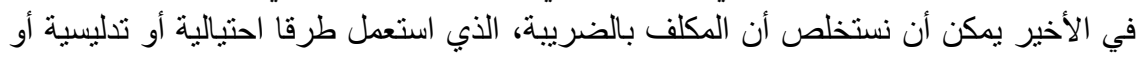

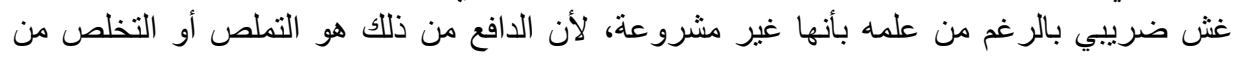

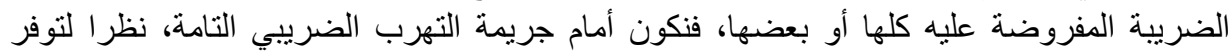
أركانها، سواء الركن المادي أو المعنوي.

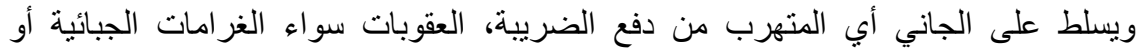

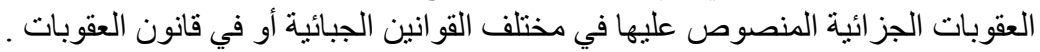

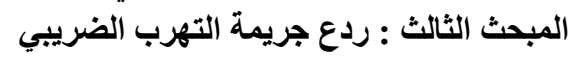

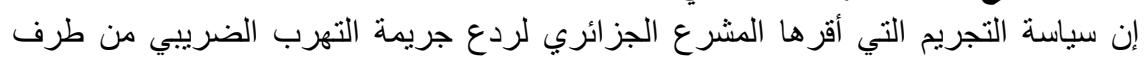

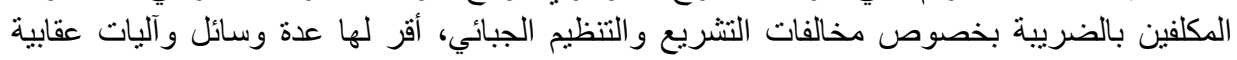
ومن أجل الحد من هذه الجريمة، نم تقرير عقوبات جبائية وأخرى جزائية من أجل حماية

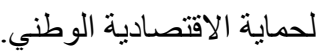

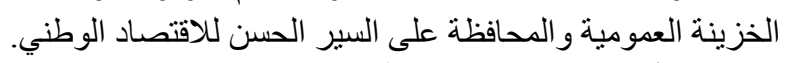
المطلب الأول : العقوبات الجبائية

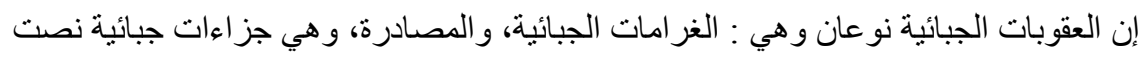
عليها مختلف القو انين الجبائية.

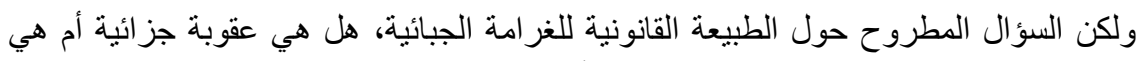

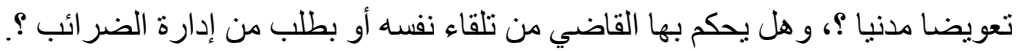

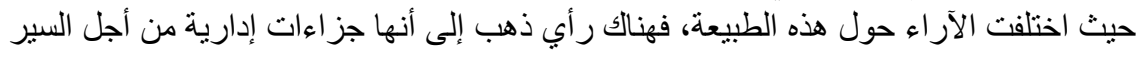

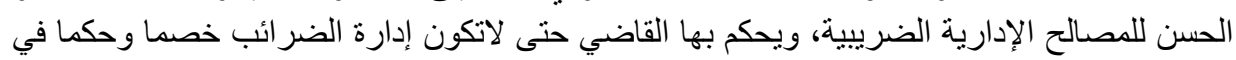

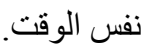

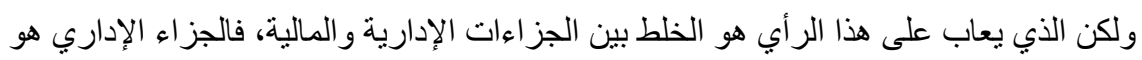

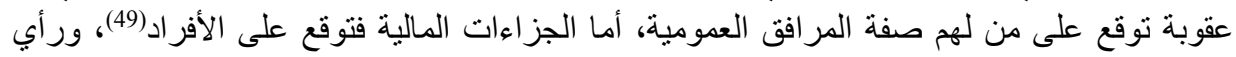

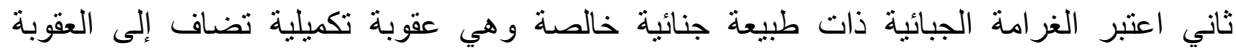




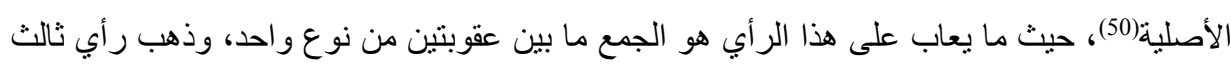

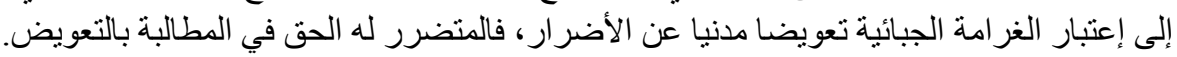

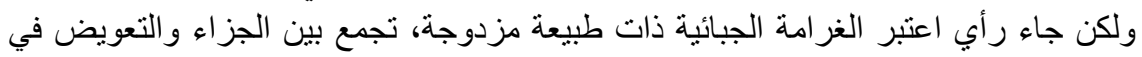

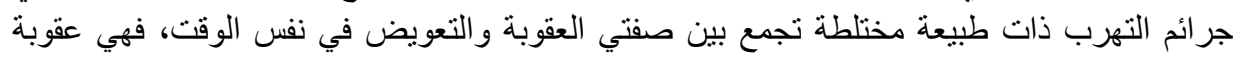

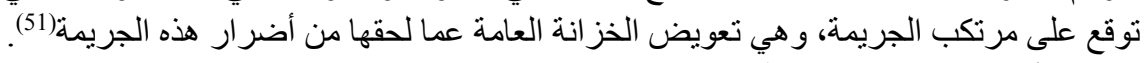
الفرع الأول : الغرامات الجبائية

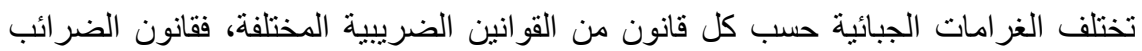

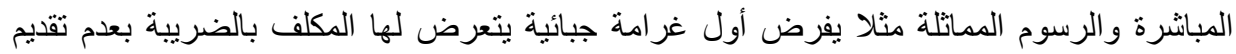

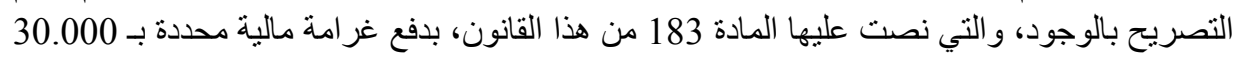

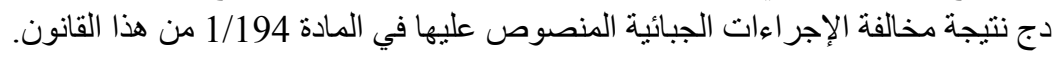

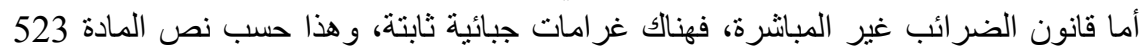

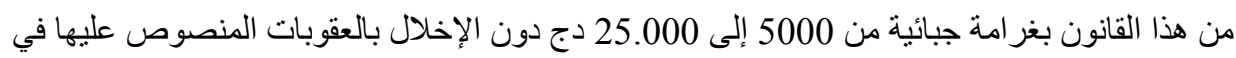

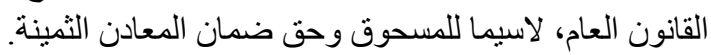

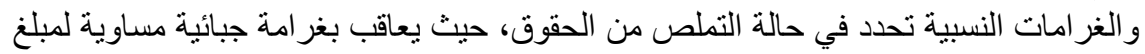

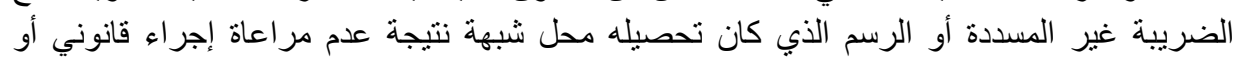

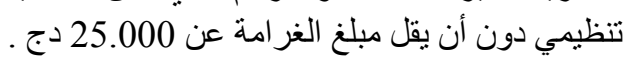

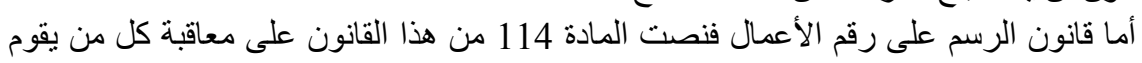

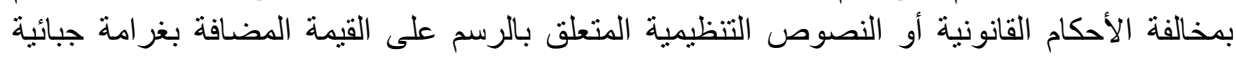
تتراوح ما بين 500 إلى 2500 دجر، وفي حالة إستعمال طرق تدليسية يحدد مبلغ الغرامة الجبائية من 1000 إلى 5000 دن. أما قانون الطابع فنصت المادة 33 من هذا القانون أنه في حالة إستعمال آلة بدون ترخيص من

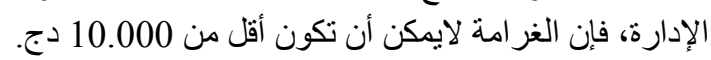

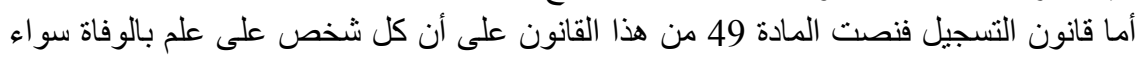

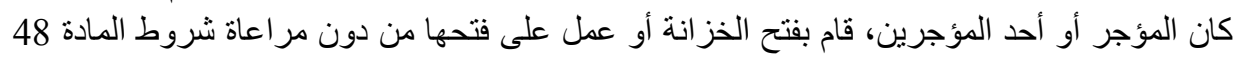

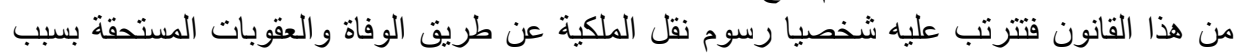

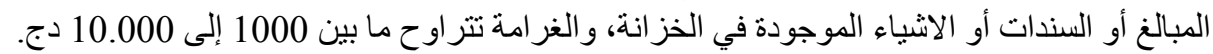

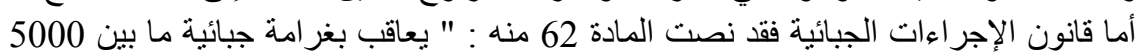

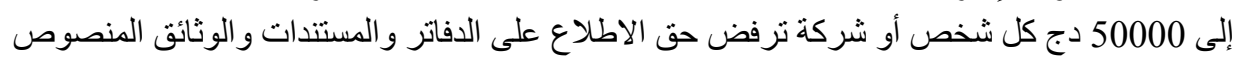

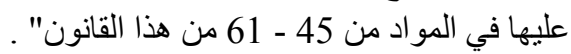

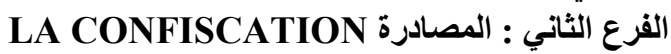

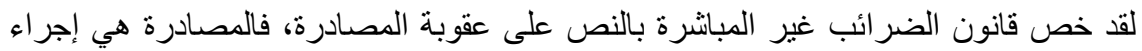

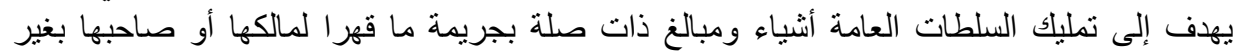

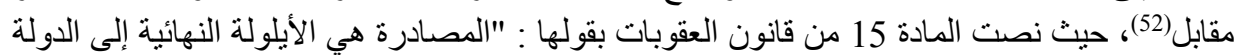

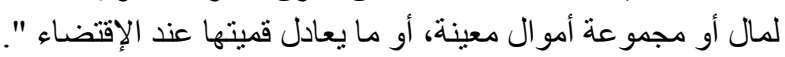

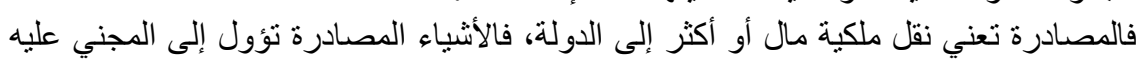

أو إلى خز انة الدولة كتعويض عما سبيته الجريمة من أضر ألثرار (53). 
حيث نصت المادة 525 من قانون الضر ائب غير المباشرة على المخالفات التي يتم قمعها ضمن

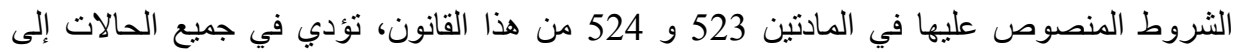

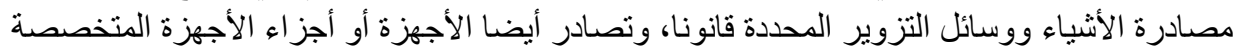

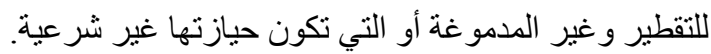
المطلب الثاني : العقوبات الجزائية

لقد نصت مختلف القوانين الجبائية، وكذلك قانون العقوبات التية على عقوبات ردعية لمرتكبي

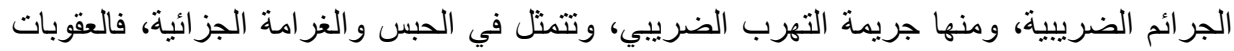
الجزائية تتقسم إلى نوعين : عقوبات أصلية تتمثل في الحبس و الغرامة، و وعقبات تكميلية تتمثل في الجز اءات السالبة للحقوق. الفرع الأول : العقوبات الأصلية

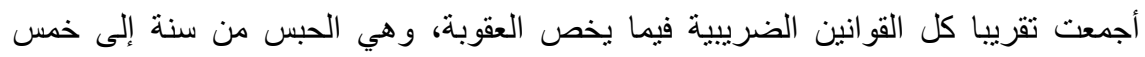

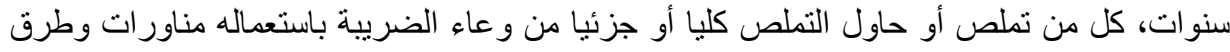
تدليسية أو إحتيالية، غير أنها تختلف بالفي النسبة لقيمة الغر امة الجزائية.

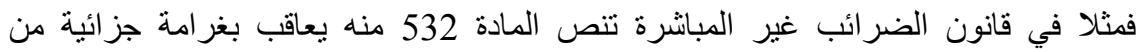

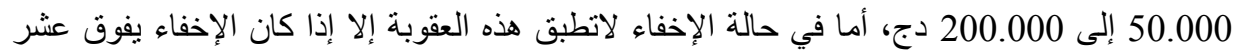
المبلغ الخاضع للضريبة. كذلك المواد 536 و 537 من قانون الضرائب غير المباشرة والمادة 304 و 908 من قانون الضرائب المباشرة، والتي تتص على أنه كل من قام بتنظيم اعتر اض أون أو رفض جماعي على أنى تأسيس

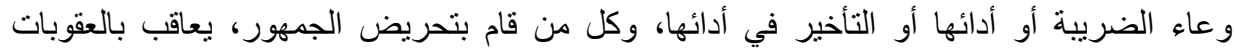

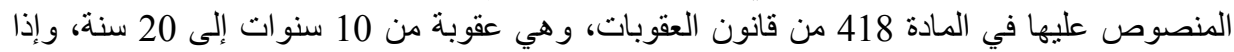
كان مرتكب الجريمة موظف أو من الاشخاص المنصوص عليها في المادة 119 من قانون العقوبات تكون العقوبة الإعدام. ولكن الإشكال القانوني المطروح حاليا هو أن جريمة الإخلال بحسن سير الاقتصاد الوطني المنصوص عليها في المادة 418 من قانون العقوبات قد ألغيث بموجب المادئ 12 من القانون الإن رقان

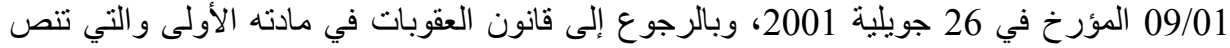

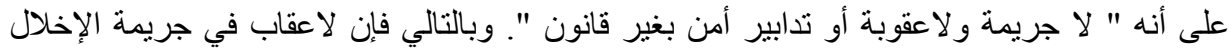

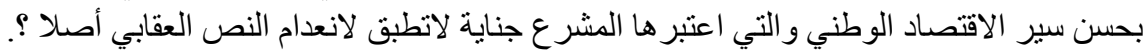
كذلك خول المشرع للقاضي سلطة تقديرية في تحفيف العقوبات، و هذا وفقا للمادة 53 من فانون

أما بالرجوع إلى القو انين الجبائية فإنها تتص صر احة على عدم إمكانية تطبيق ظروف التخفيف

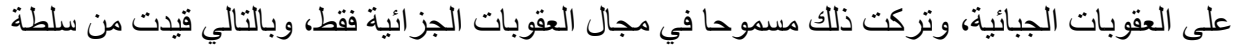
لقد تم تعديل المادة 303 الفقرة الأولى من قانون الضر ائب غير المباثرة، بالمادة 13 من القانون

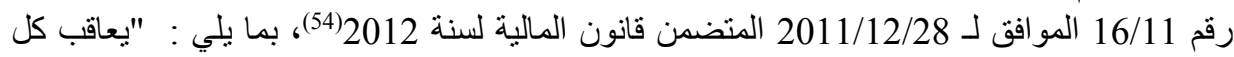

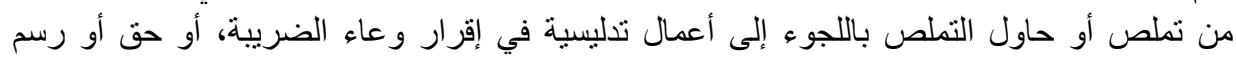
خاضع له أو تصفيته كليا أو جزئيا بما يأتي : 


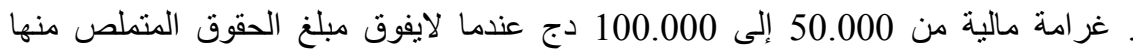

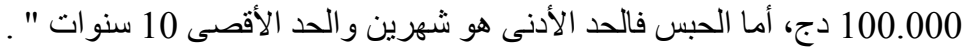

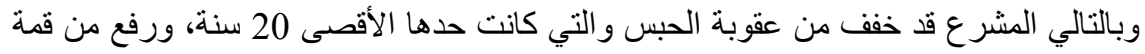

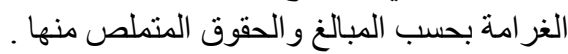

الفرع الثاني : العقوبات التكميلية النية

نجد أن القو انين الضريبية تضمنت العقوبات التكميلية، إلى جانب العقوبات الأصلية، وهذا من

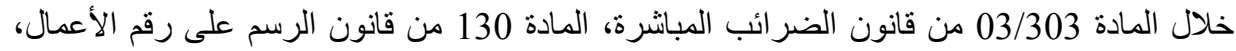

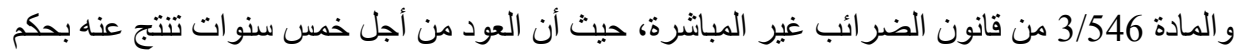

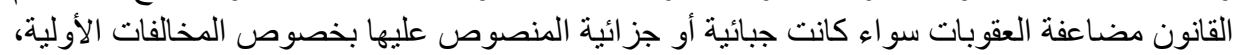

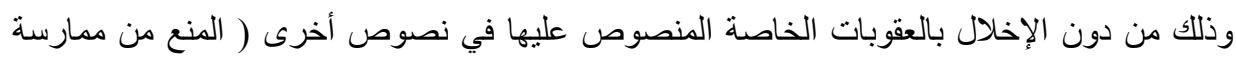

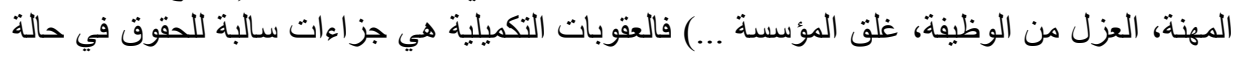

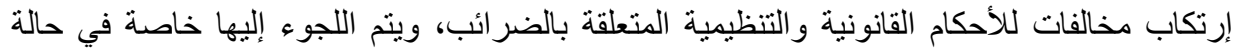
العود بالنسبة لفئة من فئات المهن الحرة.

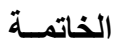

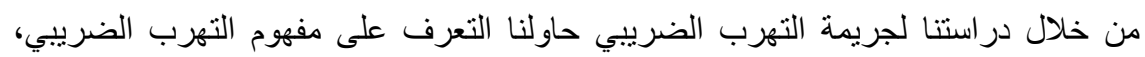

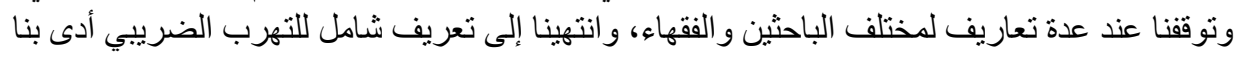

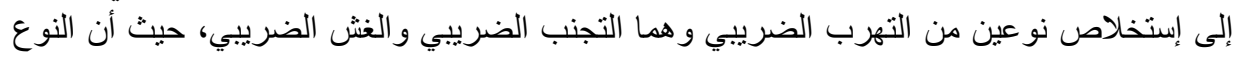

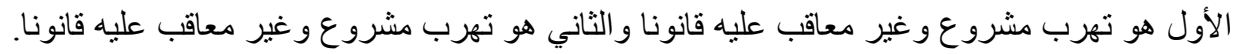

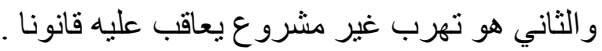

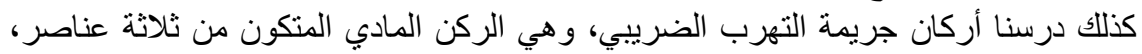

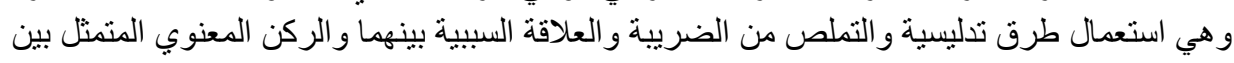

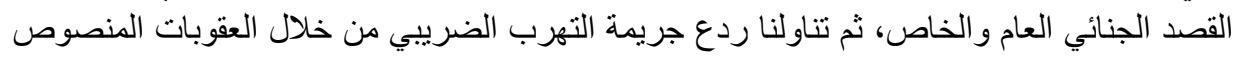

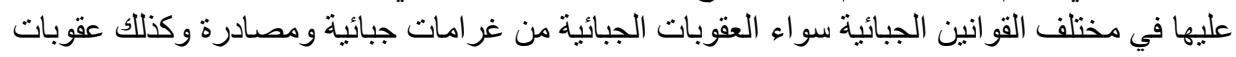
جز ائية سو اء العقوبات الاصلية وكذللك التكميلية.

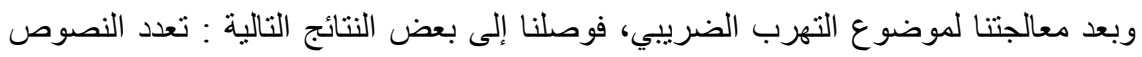

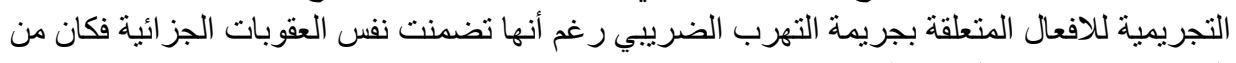

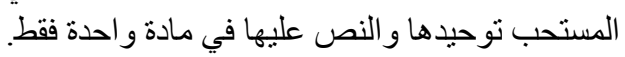

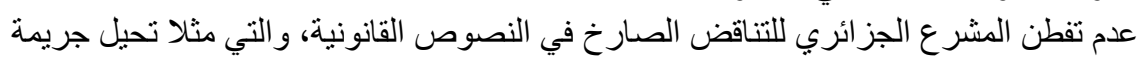

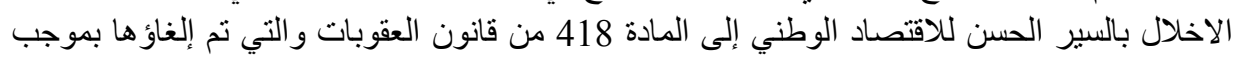

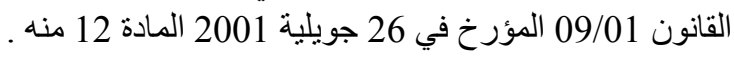

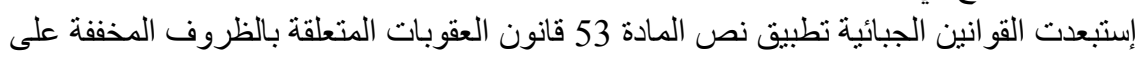

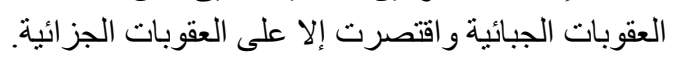

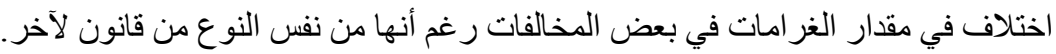

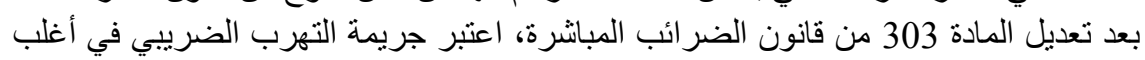

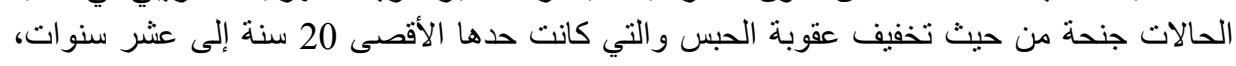

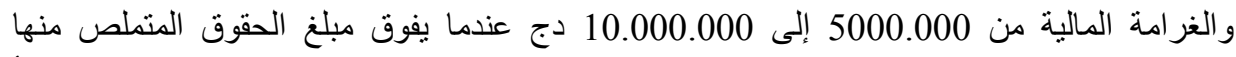
10.000.000 دج، في هذه الحالة فقط تعتبر جنائية، و هذا سعيا من المشر عن تحقيق التوازن ما بين مبدأ 
النفعية لتمويل الخزينة، وما بين مبدأ العدالة الاجتماعية وردع المتهربين بالعقوبات الجزائية الحبس

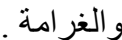

نصت كل القو انين الجبائية على أن تجمع العقوبات من أجل ردع المخالفات في المجال الجبائي

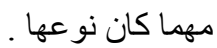

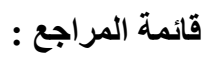

(1) ـ ناصر مراد : التهرب و الغش الضريبي في الجزائر، دار قرطبة للنشر و التوزيع، 2004، ص

(2) - BOUZAT (P) et PINATE (J) : Traité de Droit Penal et de Criminologie,

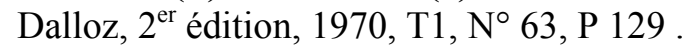

(3) ـ نبيل صقر : الوسيط في شرح قانون العقوبات الخاصة الجريمة الضريبية والتهريب، دار الهدى،

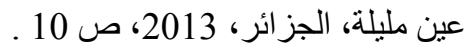

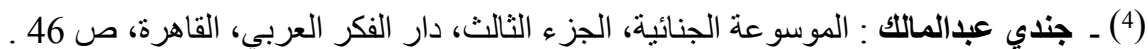

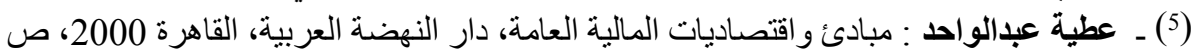

(6) ـ مجدي محمد علي الخولي : جريمة التهرب الضريبي، رسالة دكتور اه، كلبة الحقوق، جامعة

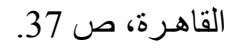

(7) ـ محمد عبدالرزاق هلهود : التهرب من الضر ائب، مجلة التشريع المالي و الضريبي، العدد 262،

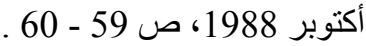

(8) - جميل عبدالرحمن صابوني : التهرب الضريبي الدولي للشركات، عابرة القوميات، دراسة مقارنة،

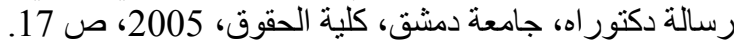

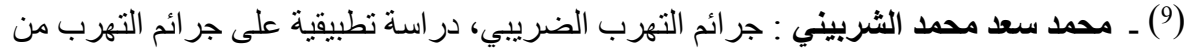

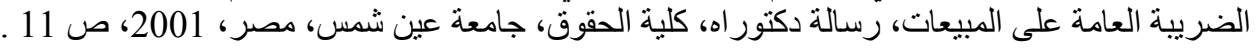

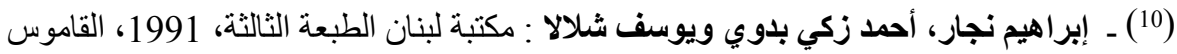

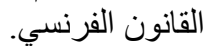

(11) ـ يحي الصافي : الغش الضريبي، الهلال العربية للطباعة والنشر، الرباط، 1996، ص 03.

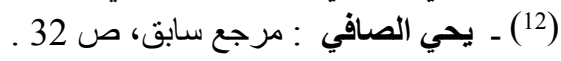

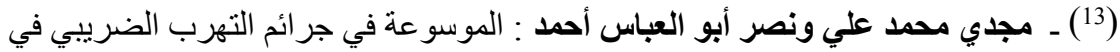

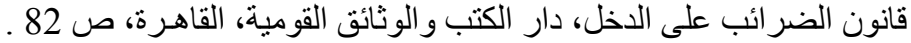

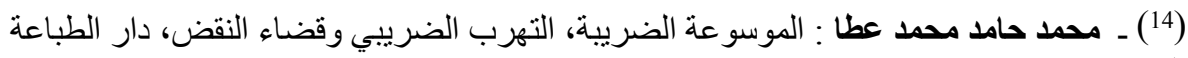

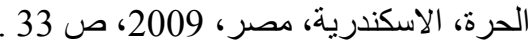

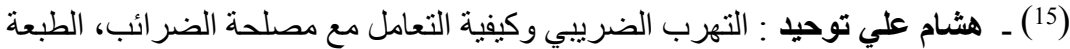

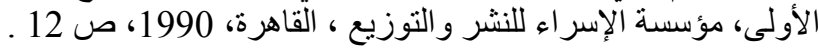

(16) - WILLIAM (B) BARKER : The Ideology of Avoidance, paper was Presanted at the loyola University chicago law, journal Conference Tax Lawin Aliberal Democracy : Exploring The Relationship, Between Tax And Good Goverance, Barker, Doc. 4.01.2009.

$$
\begin{aligned}
& \text { (17) ـ رمضان صديق : التجنب الضريبي بين الإباحة و الحضر في التشريع المقارن }
\end{aligned}
$$

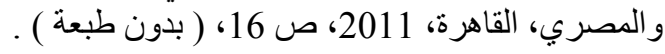

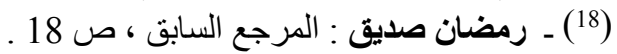


$\left({ }^{19}\right)$ - GAUDEMENT (P M) : Precis des Finances Publique, Edition Montchvertion, Paris 1970, P 314.

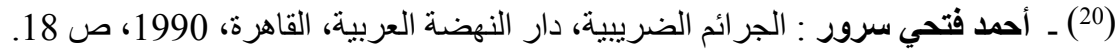

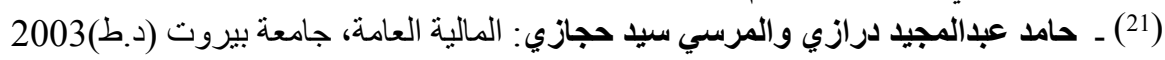

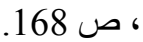

(22) - MASSON (S R) : La Notion D'évation Fiscale en Droit Interne Français, LGJ, Paris, 1990, P 181 .

(23) - MARGAIRAZ ANDRE : La Fraude Fisale et ses Succédanés Comment on échappe a L'impot, 1960, P 26.

(24) - BRUONO TADDEI : La Fraude Fiscale, Librairies Techniques, Cour de Cassationm Paris, 1974, P 54.

(25) - MARGAIRAZ ANDRE : La Fraude Fisale, OP Cit , P 28.

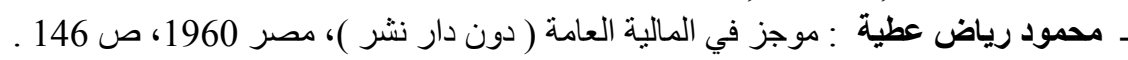

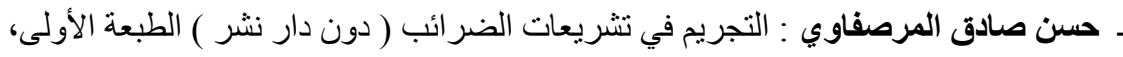

(28) ـ دولار علي وعبدالمنعم فوزي : مالية الدولة، منشأة المعارف، الإسكندرية، مصر، 1962، ص

(29) ـ أحمد جامع : علم المالية العامة، الجزء الأول، مكتبة السيد عبداله و هبة، القاهرة، 1965، ص

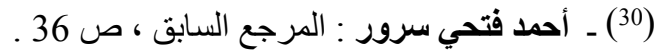

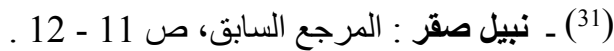

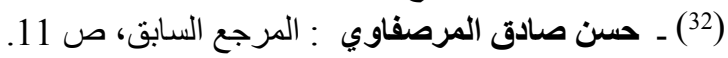

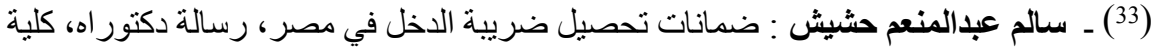

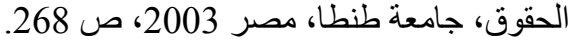

(34) ـ محمود مصطفى : الجر ائم الاقتصادية في القانون المقارن، ج1، الأحكام العامة و الاجر اءات

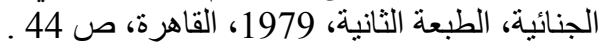

(254) ـ محمود نجيب حسن : شرح قانون العقوبات، القسم العام، دار النهضة العربية، مصــر 1982،

ص 264 صود

(36) - ROBERT (J H) : Droit Pénal Géneral, Presses Universitaires de France, 3er , 1998, P 194.

(37) ـ مجدي محمد علي الخولي : الموسو عة في جر ائم التهرب الضريبي ( دون دار نشر )، مصر ،

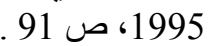

(38) ـ حسني الجندي : القانون الجنائي الضريبي، دار النهضة العربية، 2006/2005، الجزء 1 و 2،

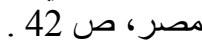

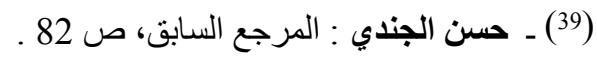

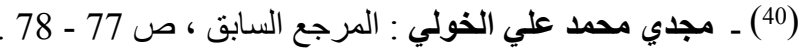

(41) ـ مأمون محمد سلامة : قانون العقوبات، القسم العام، طبعة 136 لـ 1991/1990، دار النهضة العربية،

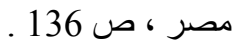




$$
\begin{aligned}
& \text { (42) ـ أحمد فتحي سرور : المرجع السابق ، ص ص } 121 \text {. }
\end{aligned}
$$

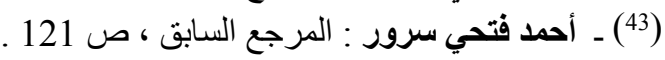

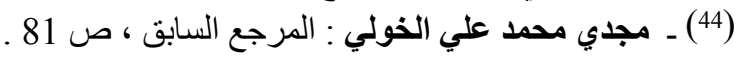

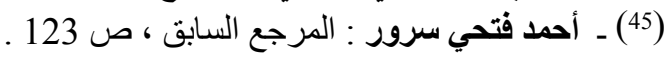

(46) ـ محمد أحمد محمد منتصر : الركن المعنوي في جريمة التهري التهرب الضريبي، در استة مقارنة،

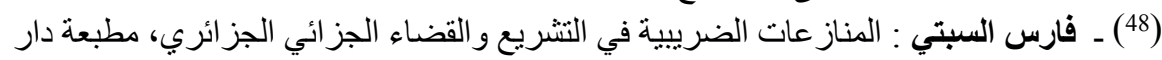

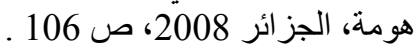

(49) ـ البثري الثوريجي : جرائم الضر ائب و الرسوم، دار الجامعات المصرية، الطبعة الأولى، مصر

(50) ـ محمد عوض : مأ جر ائم المخدرات و التهرب الجمركي و النقدي ( دون دار نشر )، 1962، ص

(51) - روؤوف عبيد : مبادئ القسم العام في التشريع الجنائي، دار الفكر العربي، 1979، ص 1968 ـ 719.

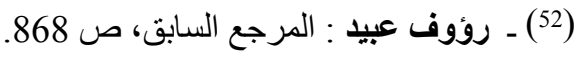

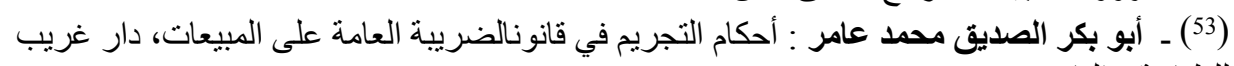

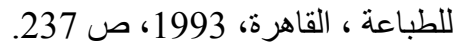

(54) ـ الجريدة الرسمية رقم 72 الصادية بتاريخ 2011/12/29. 